\title{
As vicissitudes da pesquisa e da teoria no campo da política social
}

\author{
Potyara A. P. Pereira
}

\section{Introdução}

É fato conhecido que nenhuma disciplina científica ou corpo sistematizado de conhecimentos é produzido sem o concurso da pesquisa. Mas, o que nem todos sabem é que a construção do conhecimento não depende só do uso correto, competente e imaginoso de metodologias. Ao lado da aplicação de métodos e técnicas de captação e compreensão da realidade, há de se proceder previamente à delimitação do campo temático do estudo, ou a demarcação da problemática central, a partir do qual será possível decidir pela metodologia mais apropriada. É que sem uma definição adequada da temática, muitas descobertas ditas científicas, porque baseadas apenas em metodologias confiáveis, tornam-se pouco pertinentes e sem sentido de prioridade. Daí por que toda e qualquer produção de conhecimento científico precisa realizar a unidade de duas dimensões principais: a metodológica e a substantiva.

É com base nessa exigência que irei discorrer sobre as vicissitudes da pesquisa no campo da política social, tendo o cuidado de não descurar da teoria em favor da metodologia. Isso não significa que, do ponto de vista substantivo, a política social já esteja suficientemente equipada. Pelo contrário, é sobejamente conhecido que a construção da teoria neste campo de estudos e ações, ainda é uma meta a ser atingida e um desafio cognitivo a

${ }^{*}$ Pesquisador associado do NEPPOS/CEAN/UnB, professor risitante da Faculdade de Serviço Social da UERJ. 
ser enfrentado. Mas, não obstante esse fato, já é possível identificar no âmbito da política social um acúmulo ordenado de reflexões, hipóteses e interpretações, baseado em evidências empíricas, a partir do qual se pode identificar um conteúdo próprio. O que não pode ser feito é, sob o pretexto da fragilidade da teoria e da vocação intervencionista da política social, cair no pragmatismo, sob pena de mantê-la eternamente prisioneira do senso comum.

Um outro aspecto a ser levado em conta, a título de observação preliminar, é a possível influência do chamado ambiente societal da pesquisa sobre o pesquisador, ou seja, a possibilidade de certos condicionantes políticos, sociais, culturais e intelectuais influenciarem direta ou indiretamente a produção do conhecimento. Sendo o pesquisador membro de uma dada sociedade, a sua atividade poderá ser, ou não, legitimada dependendo do que for considerado relevante e prioritário pelo sistema sociocultural prevalecente.

Dentre os condicionantes que mais comumente influenciam a pesquisa, destacam-se:

a) o imperativo da demanda social;

b) os valores prevalecentes;

c) a força do senso comum.

Os imperativos da demanda social tendem a colocar a pesquisa a serviço de questões ou temáticas valorizadas de tempos em tempos, seja pela força da difusão cultural, seja pela necessidade do sistema encontrar saídas ou respostas para problemas prementes. Assim, as encomendas e o financiamento, feitos para que se investiguem essas questões ou temáticas, podem "introduzir intenções normativas que desnaturam o processo de objetivação científica” (Bruyne et al., 1997, p. 32). Além disso, há o risco de cooptação do pesquisador por grupos de pressão, ou argumentos de autoridade, fazendo-o aceitar, como "dadas", informações parciais ou "verdades" carentes de fundamentação. Enfim, o "conjunto de pesquisadores, as teorias e as experiências, os rituais e as normas, as instituições acadêmicas, exercem um controle direto sobre toda pesquisa" (Bruyne et al., 1997, p. 32).

A política social não está livre desses condicionantes e controles. Na verdade, ela tem se revelado um campo fértil para a 
sua incidência, na medida em que muitas das questões ou temáticas que Ihes são demandadas o são tendo em vista a sua legitimação ou o seu aval pela pesquisa.

Os valores prevalecentes também influenciam sobremaneira a investigaçào. Tais valores não só impõem ao pesquisador a escolha de problemas, como muitas vezes determinam a relevância de um objeto de estudo. São os valores dominantes que geralmente informam as demandas, estabelecem prioridades e conferem à pesquisa a marca da oportunidade e da atualização. Quantas vezes esforços e "achados" autônomos de investigações são considerados obsoletos, arcaicos ou anacrônicos, porque se distanciam de valores prezados por ideologias influentes! Isso é muito comum no campo da política social, no qual têm ocorrido, através dos tempos, verdadeiros assaltos intelectuais contra a pertinência científica desse tipo de política. Foi assim com as ideologias malthusiana e darwinista social, que serviram de suporte ao liberalismo clássico da segunda metade do século XVIII até fins do século XIX, assim como também foi com as postulações frankfurtianas, que, no século XX, instrumentalizaram muitas teses, ditas marxistas, contra a política social. Mais recentemente, com a ascensão da ideologia neoliberal, esses assaltos ganharam renovada expressão.

A força do senso comum, ou do campo do saber não sistematizado e comprovado, tende a contaminar com pré-noções a atividade de investigação ou a incutir no pesquisador uma "certeza sonambúlica”, no dizer de Mannheim (apud Bruyne et al., 1997), sobre a realidade que investiga e atua. Dessa forma, não é raro o fato de preocupações pragmáticas substituírem esforços criteriosos de construção teórico-metodológica, prevalecendo, na prática da política social, procedimentos mecânicos e intuitivos.

Tal tendência tem sido usual na história da política social, a ponto de alguns autores - como será visto adiante - não lhe reconhecerem o status de disciplina ou de um corpo sistematizado de conhecimento.

Isso posto, vejamos, em primeira aproximação, os elementos que definem e balizam o conteúdo substantivo da política social, os quais deveriam ser levados em conta pela pesquisa nessa área. 


\section{Qualificação do conteúdo da política social}

O campo de problemáticas da política social é vasto e, por isso, não pode ficar confinado a uma única área de conhecimento. Dessa forma, ele é, por natureza, um espaço interdisciplinar, no qual cada disciplina - Serviço Social, Sociologia, Economia, Ciência Política delimitam um aspecto particular desse espaço epistêmico para nele trabalhar. Tal cometimento pode apresentar prós e contras, pois, se, por um lado, ele propicia a construção de saberes especializados, indispensáveis à compreensão do todo, por outro lado pode incentivar o isolamento intelectual e a fragmentação desses saberes (Pereira, 1992, p. 45).

Entretanto, independentemente do fracasso ou do êxito do trabalho interdisciplinar, o que importa reter nesta reflexão, é que a inteligibilidade e a eficácia da política social só poderão ser alcançadas mediante a vinculação orgânica de diferentes achados científicos produzidos por disciplinas particulares. Daí porque, nas tematizações mais promissoras da política social percebe-se claramente a relação de mútua implicação entre três esferas chaves: Política, Ética e Economia. Disso se depreende que, embora os métodos e técnicas utilizados por essas diferentes especializações variem, o seu objeto de interesse, e muitas vezes os seus objetivos últimos, coincidem.

Mas, além dessa particularidade, uma outra importante qualificação a ser feita é quanto ao termo política. É que este termo, componente da expressão política social, tem uma conotação especial. Ele remete a uma certa categoria de política, que corresponde a um campo de investigação e ação muito mais identificado com os processos de tomada de decisão e de definição de estratégias de intervenção do que, propriamente, com os temas clássicos da política, como: partidos, eleições, voto, governo, etc. Está certo que esses temas clássicos interessam aos estudiosos da política social pelas interfaces que mantêm com o seu objeto de interesse e por comporem com ele um contexto mais amplo de compreensão e percepção do fenômeno político. Mas, o assim chamado núcleo duro da política social é o da política como processo ativo e positivo de decisão com vista à intervenção social; ou, em outros termos, é o da política como linhas de orientação para a ação pública, em 
resposta a legítimas demandas e necessidades sociais. É o que na língua inglesa é grafado como policy, e não como politics (expressão referente aos temas tradicionais da política, acima indicados), a qual está indissoluvelmente ligada ao conceito de cidadania social (que requer efetiva intervenção do Estado) e de Welfare State (como um sistema de organização social e política que garante e provê bens públicos ${ }^{1}$ como direitos.

Portanto, quando se fala de política social, está se falando de uma política pública, ou seja, de uma política cuja principal marca definidora é o fato de ser pública, e não estatal nem privada, e nem, propriamente, coletiva. O seu caráter público é dado não pelo tamanho do agregado social que lhe demanda atenção, mas principalmente porque são decisões e ações que apresentam as seguintes características: a) revestem-se de autoridade, por terem amparo legal; b) visam concretizar direitos conquistados por parcelas da sociedade e declarados nas leis; c) guiam-se pelo princípio do interesse comum e da soberania popular e não pela soberania dos governantes; c) devem estar a serviço da satisfação das necessidades sociais e não da rentabilidade econômica privada; d) têm a conotação de res publica, isto é, coisa (res) de todos (publica). Trata-se, pois, a política social, de uma estratégia de ação pensada, planejada e avaliada, guiada por uma racionalidade coletiva, e não meramente individual, na qual tanto o Estado como a sociedade desempenham papéis ativos. Eis porque o estudo da política social - assim como o de toda política pública - é o estudo do Estado em ação (Meny e Thoenig, 1992), nas suas permanentes relações de antagonismo e reciprocidade (lanni, 1979) com a sociedade, a qual constitui o espaço privilegiado das classes sociais.

Por fim, vale ressaltar que as políticas sociais constituem, ao mesmo tempo, um campo de estudo e de investigação e um método ou conjunto de métodos de ação, o que permite a decomposição da complexa esfera da ação pública em atividades distintas, analiticamente separáveis, e a comparação de diversas situações entre si (Meny e Thoenig, 1992).

\footnotetext{
Bens, como educação, saúde, dotados das seguintes características (Rua, 1998): a) são indivisíveis, isto é, o consumo de A não impede que B tenha a possibilidade de consumir a mesma coisa; b) não podem ser ofertados com base em critérios e mecanismos do mercado; c) devem estar disponíveis, pois cada consumidor potencial tem direito de obtê-los e de desfrutá-los igualitariamente.
} 
Contudo, apesar de relativamente qualificada e pesquisada, a política social ainda é muito mal compreendida. $E$ isso se deve a vários fatores, indicados a seguir.

\section{A situação da produção do conhecimento no campo da política social}

A fraca compreensão da política social deve-se, em grande parte, à falta de um envolvimento tradicional das Ciências Sociais com essa temática. Embora a análise das ações governamentais não seja propriamente um procedimento novo, pode-se dizer que só recentemente a política pública vem se convertendo em um ramo especializado da ciência política e valorizado por diferentes disciplinas econômicas e sociais. Isso porque a política pública tem a ver com um fenômeno que só ganhou expressão em meados do século XX - a explosão do intervencionismo público-o que, por sua vez, exigiu o alargamento do escopo da temática da política. Como dizem Meny e Thoenig (1992, p. 13),

durante muito tempo a ciência política (...) apenas tangenciou o problema [das ações do Estado], tão preocupada estava em analisar e melhor compreender os fenômenos políticos em sua acepção restrita: eleições, partidos, parlamentos, governos. Os escassos intentos interpretativos, unindo a ideologia ao senso comum, estabeleciam um nexo de causalidade muitas vezes vago entre, por exemplo, a maioria no poder e as políticas públicas perseguidas.

Foi, portanto, com o desenvolvimento e a consolidação do Welfare State, após a Segunda Guerra Mundial, que as políticas públicas ganharam consistência analítica e interpretativa,

Mas, mesmo assim, o interesse intelectual pelo Welfare State não se deu de imediato, nem em correspondência com as suas expressão e influência nas sociedades capitalistas avançadas, a despeito de ele ser:

- um conceito intelectual e estrategicamente importante, que provê, simultaneamente, base comum para diferentes enfoques (sociológicos, econômicos, políticos, éticos) e para a integração da teoria com a História e com a Política; 
- um fenômeno indubitavelmente marcante na história das sociedades capitalistas do pós-Segunda Guerra e, portanto, um veio analítico privilegiado para o entendimento da dinâmica do capitalismo regulado;

- um campo de estudos que vem sistematicamente escapando das amarras das interpretações parciais, setoriais ou simplistas, e impondo, à direita e à esquerda, constantes revisões.

Vários foram os fatores que contribuíram para essa renitente negligência cognitiva. O principal, segundo Roche (1992) e Pierson (1991), foi a forma ortodoxa - para não dizer dogmática - como pensadores de diferentes persuasões perceberam e explicaram o surgimento e a fantástica expansão do Welfare State entre os anos 1950 e 1960.

Para a direita, por exemplo, o Welfare State seria uma medida político-institucional nociva e perigosa, pois abalaria as premissas fundamentais da ideologia liberal, como a liberdade negativa (que nega a intervenção pública), especialmente a do mercado, conquistada pelos movimentos revolucionários burgueses dos séculos XVII e XVIII.

Para certos setores da esquerda, por sua vez, o Welfare State também seria nocivo e perigoso, só que com base em outras argumentações: ele enfraqueceria a disposição da classe trabalhadora para lutar por mudanças estruturais.

É importante notar que, embora diferentes quanto à persuasão, muitos dos ataques da esquerda à proteção social pública reforçaram a tese da direita da incompatibilidade de convivência de uma economia de mercado com um sistema de provisão social regulado publicamente. Era assim que entendia Adam Smith, para quem o bem-estar social seria a soma dos bem-estares individuais obtidos através dos mecanismos de livre escolha, associados ao mercado. Mas, também era em nome dessa incompatibilidade que o marxismo clássico ${ }^{2}$ sustentava a convicção de que a ordem econômica

2 Isso não significa que Marx não tenha aplaudido a luta da classe trabalhadora, no século XIX, por uma legislação - que deveria regular as relações de trabalho fabril e impor um limite à exploração despótica da força de trabalho pelo capital - e entendido a conquista trabalhista dessa legislação como a vitória de um princípio, qual seja: o de que é possível, no interior do sistema capitalista, impor exigências identificadas com uma economia política do trabalho contra a lógica da economia política do capital. 
capitalista seria incapaz de prover bem-estar social e individual, seja por meio do mercado ou do Estado.

Têm-se, assim, já a partir do pensamento clássico, uma categórica negação à serventia do Estado na provisão do bemestar, o que, sem dúvida, contribuiu para minimizar, no século $X X$, a importância das políticas sociais como objeto de interesse teórico.

Tal idiossincrasia continuou existindo, mesmo quando, com a incontestável consolidação e amadurecimento do Welfare State, depois da Segunda Grande Guerra, imperou um certo consenso entre esquerda e direita de que havia, na realidade, uma simbiose entre capitalismo e provisão social pública. Só que, enquanto a direita e certos setores de esquerda, como a social-democracia, encararam a expansão das políticas públicas como algo dado ou uma conseqüência automática do progresso econômico de PósGuerra, alguns marxistas, ao admitirem o Welfare State como um fato, concentraram sua atenção apenas nas suas conseqüências negativas para a classe trabalhadora. Teóricos da Escola de Frankfurt, por exemplo, (apud Navarro, 1983) embora não compartilhassem da visão precipitada da direita, que via na afluência econômica e no pleno emprego o prenúncio do fim da ideologia (Bell, 1977), avalizavam indiretamente essa visão ao enfatizarem o esvaziamento do poder revolucionário da classe trabalhadora, devido à cooptação desta classe pelas políticas do Welfare State.

Ora, dada a prevalência de tal percepção, não é de admirar que a teoria das políticas sociais tenha permanecido, durante décadas, à margem do interesse científico, que requer investigações contínuas e sistemáticas. Afinal, não se investiga o óbvio, o inexistente, o anacrônico, pois tais situações carecem de atração analítica.

Evidentemente que, nesse ínterim, alguns estudiosos preocuparam-se com a política social; mas, até estes, resolveram compensar o vazio teórico reinante com o pragmatismo. Foi o caso de autores conhecidos, como Titmuss, Townsend e Donnison, que, seguindo os passos reformistas de figuras de proa na construção do bem-estar inglês, como os fabianos Beatrice e Sidney Webb e William Beveridge (Mishra, 1982), passaram a se interessar mais pela força empírica dos fatos e evidências, que exigiam pronta ação, 
do que pelos complicados e abstratos exercícios de elaboração teórico-conceitual. Daí a dominância, no campo da política social, de enfoques eminentemente práticos como a Social Administration, de larga tradição no chamado Primeiro Mundo, mormente na Grã Bretanha, sob a liderança de Titmuss.

Trata-se, a Social Administration - que alguns, como Marcos Coimbra (1987), apressadamente identificam com a profissão Serviço Social - de uma abordagem influente, a partir dos anos 1960, dotada, segundo Mishra (1982), ${ }^{3}$ das seguintes características:

- É mais um campo do que uma disciplina. Por conseguinte, é uma área sem um puzzle, ou quebra-cabeça central, que exigiria teorias e metodologias apropriadas para 0 seu desvendamento. Embora Titmuss tenha refutado esse entendimento, assegurando, baseado em Donnison, que a Social Administration é uma disciplina-síntese de saberes particulares por trabalhar, simultaneamente, com conhecimentos de diferentes disciplinas, Mishra afirma que essa abordagem ainda carece de um amplo e acumulado corpo conceitual e substantivo;

- Dá ênfase a questões locais, nacionais parciais em detrimento de generalizações e inferências orgânicas e transnacionais, obtidas por meio de estudos macro e comparados. Daí surge, a meu ver, a tendência tecnocrática, tão influente no Brasil, de segmentar o campo da política social em setores e de identificar os diferentes ramos temáticos dessa política (saúde, educação, previdência, habitação e, inclusive, a assistência social) como políticas setoriais.

- Privilegia as políticas sociais estatutárias, isto é, oficiais, subestimando outras formas particulares de proteção, como as políticas sociais ocupacionais, assumidas pelo mercado de trabalho; como a filantropia, desenvolvida por instituições privadas não mercantis; como o setor informal de provisão social, constituído de agregados como a família, os vizinhos,

${ }^{3}$ Vide Mishra (1982), cuja análise serviu de eixo central para o artigo de Coimbra (1987). 
os grupos de amigos, cuja compreensão ampliaria o leque de conhecimento sobre a política social;

- É essencialmente descritiva e prescritiva e, portanto, está mais preocupada em estabelecer, na prática, nexos de eficiência operativa entre necessidades sociais e prestação de serviços.

É óbvio que, com tais caracterizações, não haveria lugar para esforços mais ambiciosos, que, para além da institucionalização, implementação, acompanhamento e controle eficientes e eficazes da intervenção, trabalhassem categorias, propriedades, inferências, visando, teoricamente, dar conta da relação complexa e contraditória entre política social, Estado e sociedade.

Contudo, após décadas de relativa indiferença, o interesse acadêmico-crítico pelo tema do Welfare State e da política social tornou-se mais consistente, especialmente a partir do final dos anos 1970. Junto com esse interesse, a tematização dos conceitos de cidadania, de seguridade social e de democracia de massas, também ganharam relevância. O fato que desencadeou essa mudança foi a séria recessão econômica mundial dos anos 1970, a qual, além de pôr em destaque as limitações dos paradigmas e enfoques pragmáticos dominantes, colocou o Welfare State no centro de um debate que mobilizou um número considerável de atores e abordagens.

Com efeito, o diagnóstico de que o Welfare State estava "em crise", e de que muitos dos problemas sociais, econômicos e políticos contemporâneos deviam-se ao fortalecimento e expansão desse Estado, durante os "trinta anos gloriosos" (para usar a expressão cunhada por Jean Forrastié, apud Robin, 1993, p. 139), transformouse no alvo preferencial das reflexões acadêmicas e na pedra de toque das críticas formuladas por novos personagens políticos. Assim, ao lado de uma "Nova Direita", constituída por representantes do neoliberalismo e do neoconservadorismo - ressuscitadores da tese da incompatibilidade da economia de mercado com a provisão social pública - surge uma "Nova Esquerda", de cujas fileiras sobressaem pensadores que assumem a política social como objeto privilegiado de estudo e a submetem a uma análise avessa às interpretações 
funcionais e valorativas. Desse modo, a política social deixou de ser definida linearmente pela sua função (de manutenção da ordem, produtiva, desmobilizadora ou mobilizadora), pela sua índole (boa ou má, positiva ou negativa) e pelo seu grau de desenvolvimento (atrasada, adiantada), para ser encarada como um fenômeno contraditório (Gough, 1979) que, dependendo da correlação de forças em presença, pode ser ao mesmo tempo a tese e a antítese. Da mesma forma, deixou de ter cabimento falar de Welfare State como um fenômeno unívoco, isto é, não diferenciado no espaço e no tempo, e de medi-lo por uma escala de graus de generosidade e de desenvolvimento. Uma evidente rejeição a essa tendência, é a classificação de Esping-Andersen (1991) dos vários tipos existentes de Welfare States, distinguindo-os pelos regimes políticos aos quais pertencem (liberal, conservador, social democrata).

Paralelamente ao surgimento dessas novas vertentes, livres do vício metodológico de analisar a política social pelo ângulo da sua funcionalidade (o que descamba para o funcionalismo), é digno de nota o envolvimento de frações dos "novos movimentos sociais" (ecológico, feminista, anti-racista, dentre outros), na tematização do significado e alcance dessa política no capitalismo. Dessa tematização, várias críticas endereçadas ao produtivismo e industrialismo e dos seus impactos nefastos sobre a qualidade de vida da humanidade, assim como da incapacidade do Welfare State em estender bens públicos como direitos, foram respaldadas em pesquisas. E, com base nessas pesquisas, surgiram propostas inovadoras alternativas de política social, que impuseram novas titularidades e garantias no campo da política social, e introduziram novos conceitos no âmbito da cidadania.

Isso explica a mudança de tratamento do Welfare State nos círculos intelectuais e políticos dos últimos trinta anos. No chamado Primeiro Mundo, ganham espaço os Departamentos de Política Social nas universidades, os quais, em substituição aos antigos Departamentos de Social Administration, desenvolvem relevantes reflexões teóricas nesta área. Hoje, já é possível contar, especialmente na Europa, com um elenco de intelectuais de elevada qualificação, especializados na temática da política social. Valorizam-se, também, nas universidades e centros de pesquisas, estudos comparados, ${ }^{4}$ 
ao mesmo tempo em que ocorre crescente incorporação da política social pela teoria política e pela nova economia política. Isso faz com que as reflexões em torno das políticas sociais percam o seu antigo caráter "utilitário" e "prático", identificado apenas com questões nacionais ou domésticas. Conduz, ainda, para uma frutífera instrumentação da moderna teoria econômica para a compreensão dos processos políticos, e, portanto, para o conhecimento de como os diversos sistemas políticos fazem as suas opções fora da lógica do mercado (Frank, 1980).

Por conseguinte, a partir dos anos 1980 ou, mais precisamente, dos anos 1990, as políticas sociais deixaram de ser vistas como uma ilha habitada por personagens predominantemente envolvidos com uma agenda prática e localizada de combate à pobreza, para transformar-se em um complexo objeto de investigação e ação. Como diz Esping-Andersen (1991, p. 1-2),

- Welfare State tem sido focalizado por meio de duas visões: uma restrita e outra ampla. A visão restrita o prende à tradicional prática da mitigação social, identificada com transferências de renda e serviços sociais e, em alguns casos, com subsídios à moradia. A visão ampla, ao contrário, freqüentemente relaciona a questão do bem-estar com a economia política, centrando o seu interesse no papel mais amplo do Estado em organizar e regular a economia. Nesta visão, questões de emprego, salário e todo um espectro macroeconômico são também encaradas como partes integrais do complexo que conforma o Welfare State e suas políticas.

É por esta visão ampla - que eu costumo chamar de lato sensu -, inaugurada por autores neomarxistas, desde o final dos anos $1970,{ }^{5}$ que serão, a seguir, pontuadas, no campo da política social, as principais inferências, resultantes de pesquisas, as quais, contrariando liberais e conservadores, apontam para novas direções analíticas.

\footnotetext{
4 A análise comparada dos fenômenos políticos é antiga. Dizem, inclusive, que Aristóteles ou Maquiavel analisavam tudo por comparação, já que é difícil classificar, definir modelos, detectar a freqüência de acontecimentos, compreender diferenças e particularidades, sem recorrer a esse recurso metodológico. O que é novo, é o uso da análise comparada no campo específico das políticas públicas ((Meny e Thoenig, 1992, p. 223).

5 Cf o clássico livro de lan Gough, Political Economy of Welfare State, publicado em 1979 e traduzido para o espanhol em 1982.
} 


\section{Principais produtos de uma visão reconceituada e crítica da política social}

a) o Welfare State e a política social não estão em "crise", se por crise entende-se colapso, falência ou extinção; mas estão passando por um processo de reestruturação, que os obriga a abandonar antigos paradigmas e objetivos para adaptarem-se a novas mudanças estruturais e políticas. É evidente que, nesse processo, eles estão sofrendo uma forte guinada para a "direita", fortalecendo o modelo liberal de bem-estar social, que sempre vigorou em determinados países (Estados Unidos, por exemplo), concomitantemente com outros modelos adotados por países de orientação não-liberal (os sociais democratas, por exemplo). Isso indica duas principais evidências:

- que não existe apenas um único modelo de Estado de Bem-Estar e de política social, que estariam falidos devido à supremacia do mercado como agente regulador contemporâneo;

- que é a política social da social democracia que está em xeque, no rastro do colapso - esse sim! - do padrão keynesiano de regulação social, a ponto de, hoje em dia, falar-se muito mais de uma crise paradigmática do Welfare State, do que propriamente de sua extinção. O aparecimento de novas formas de políticas sociais coloca-se, contemporaneamente, como uma necessidade impostergável e imprescindível. Tanto é assim que, como informa Abrahamson (1995), a política social tem sido, nos anos recentes, muito valorizada pelos organismos supra nacionais (ONU, OCDE, etc.), sob o argumento de que ela pode contribuir sobremaneira para a "coesão social", atualmente abalada pelos altos índices de pobreza e de "exclusão social", além de ser uma pré-condição importante para a eficiência e competitividade econômicas.

b) No rastro da crise de regulação social democrata da política social, ganha destaque a chamada crise dos paradigmas, pelos quais guiava-se esse padrão de política, a saber: 
- o receituário keynesiano de regulação econômica e social, o qual, entre os anos 1930 e 1970, passou a ser a principal referência do Welfare State, com suas propostas de intervenção do Estado na economia, para assegurar altos níveis de atividade econômica, de consumo e de emprego;

- As recomendações de William Beveridge, as quais serviram de base para a construção de um unificado sistema de seguridade social, e que funcionaria como uma rede de proteção para todos os cidadãos contra doenças, desemprego e abandono. Esse sistema atuaria em duas frentes: com políticas contributivas, amparadas no seguro social, e com políticas distributivas ou de assistência social junto aos impossibilitados de contribuir para o sistema;

- a concepção trifacetada de cidadania, de T. H. Marshall que, nos anos 1950, incluiu na categoria de direitos os serviços sociais, privilegiando o Welfare State como a instituição mais diretamente relacionada com esses direitos (Pereira, 1994).

Efetivamente, tal paradigma encontrou o seu limite no final dos anos 1970, principalmente porque a reconstituição da economia política internacional alterou definitivamente as condições e as circunstâncias nas quais ele operava - pleno emprego, instituição de serviços sociais universais e extensão da cidadania social. Hoje, os altos níveis de desemprego, o crescimento de mercados de trabalho segmentados e desregulados e de novos padrões de consumo, estão a encorajar a eleição de novos arranjos políticos e mudanças na alocação dos gastos, para dar conta de articular novos interesses que surgem como resultado dessa situação. Assim, é provável que, em lugar do crescimento dos gastos sociais, da universalização dos serviços sociais e da extensão da cidadania, consolide-se um sistema eminentemente baseado no seguro social, na privatização, na focalização dos programas sociais na pobreza extrema, no mutualismo, no voluntariado, na auto-ajuda e, conseqüentemente, um sistema mais propício a apenar e estigmatizar o pobre. Isso, sem falar na tendência de prevalecimento do wokfare (bem-estar em troca de trabalho), em substituição ao welfare (bem-estar incondicional), e de estabelecimento de um novo paradigma que, conforme Abrahamson (1995), vem sendo chamado de schumpeteriano, por 
reforçar a ética capitalista do trabalho e a rentabilidade econômica privada.

Entretanto, como diz Mishra (1991), a despeito do colapso do keynesianismo, e do advento do neoliberalismo, a proposta de seguridade social, para além do seguro, e os pleitos por justiça social, continuam atuais. Em vista disso, novos paradigmas e novas concepções de direitos e deveres de cidadania estão sendo pensados e articulados por protagonistas sociais que, no auge do Welfare State, nem sequer chegaram a ser adequadamente atendidos (mulheres, negros, migrantes, idosos, portadores de deficiência, etc.). Da mesma forma, um exame mais acurado do sentido da "crise" que, desde os anos 1980, vem sendo veiculado para justificar a retração da proteção social pública como direito, precisa ser desmistificado. A esse respeito pesquisa realizada na Europa, nos anos 1990, revelou que tal sentido de crise (fiscal, de legitimidade e de eficiência do Estado) perde toda a consistência quando confrontado com a ausência real de uma crise propriamente financeira nos países capitalistas centrais; com a existência de legitimidade das políticas sociais por cerca de $70 \%$ dos entrevistados; e com a falta de eficácia da iniciativa privada em garantir o bem-estar social e resolver os problemas da "exclusão social" (Conference of the Irish Presidency of the European Union, 1996).

Portanto, longe de se querer resgatar o modelo keynesiano de bem-estar (o que seria improvável e indesejável), está-se querendo, com o concurso da pesquisa e da teoria, desmistificar as teses neoliberais com argumentos e propostas de ações que, ao exorcizarem as atuais formas de opressão capitalista, apontem para a criação de oportunidades para o exercício de novas formas de democracia e de cidadania. 


\section{Bibliografia}

ABRAHAMSON, Peter. Regimes europeos del bienestar y políticas sociales europeas: convergencia de solidariedades? In: SARASA, Sebastià; MORENO. El estado del bienestar en la Europa del Sur. Madrid: CSIC, 1995.

BELL, Daniel. O advento da sociedade pós industrial. São Paulo: Cultrix, 1977.

BRUYNE, Paul et al. Dinâmica da pesquisa em Ciências Sociais. Rio de Janeiro: Francisco Alves, 1977.

COIMBRA, Marcos A. Abordagens teóricas ao estudo das políticas sociais. In: ABRANCHES et al. Política social e combate à pobreza. Rio de Janeiro: Zahar, 1987.

CONFERENCE OF THE IRISH PRESIDENCY OF THE EUROPEAN UNION. Report. Dublin, 1996.

ESPING-ANDERSEN, Gosta. The three worlds of welfare capitalism. Cambridge: Polity Press, 1991.

FRANK, Jürgen. A nova política econômica: crítica da teoria econômica clássica? In: VOGT, Winfried et al. Estado e capitalismo. Rio de Janeiro: Tempo Brasileiro, 1980.

GOUGH, Ian. The political economy of the Welfare State. London: MacMillan, 1979. [traduzido para o espanhol: Economía política del Estado del bien-estar. Madrid: H. Blume, 1982].

IANNI, Otávio. Classe e nação. Rio de Janeiro: Civilização Brasileira, 1979.

MARX, Karl. Legislação fabril (cláusulas sanitárias e educacionais), sua generalização na Inglaterra. In: MARX, Karl. O capital. São Paulo: Abril Cultural, 1984. v. 1, t. 2.

MENY, J.; THOENIG, J. C. Las políticas publicas. Barcelona: Ariel, 1992.

MISHRA, Ramesh. Society and social policy: theories end practice of welfare. London: MacMillan, 1982.

NAVARRO, Vicente. Produção e Estado de Bem-Estar: o contexto politico das reformas. Lua Nova, São Paulo, n. 28-29, p. 157-199, 1993 
PEREIRA, Potyara A. P. Política social: um espaço para a interdisciplinaridade. Humanidades, Brasília, v. 8, n. 4, p. 454-456, 1992.

A política social no contexto da Seguridade Social e do Welfare State: a particularidade da assistência social. Serviço Social e Sociedade, São Paulo, v. 19, n. 56, p. 60-76, mar. 1998.

PIERSON, Christopher. Beyond the Welfare State? Cambridge: Polity Press, 1991.

ROCHE, Maurice. Rething citizenship: welfare, ideology and change in modern society. Cambridge: Polity Press, 1992.

ROBIN, Jacques. Os caminhos para uma sociedade de "plena atividade"e não mais de "pleno emprego". Revista de Debate Político, Salvador, n. 6, p. 135-145, jul. 1993.

RUA, Maria das Graças. Análise de políticas públicas. In: RUA, Maria das Graças; CARVALHO, Maria Izabel Valadão de (Orgs.). O estudo da política: tópicos selecionados. Brasília (DF): Paralelo 15, 1998. p. 231-260. 